\title{
NON-INVASIVE AND MINIMUM INVASIVE CONCEPTS IN PREVENTION, CARIOLOGY AND ENDODONTICS - FROM RESEARCH AND SCIENCE TO PRACTICE
}

\author{
E. Boteva \\ National Consultant in Operative Dentistry, Endodontics and Periodontology \\ Conservative Dentistry, Dental Medicine - Sofia, Bulgaria
}

\begin{abstract}
The minimum invasive dental concept is based on practical experience of more than 30 years negative trends from the use of resin materials in distal teeth and early metal-ceramic "aesthetic" crowns and bridges. The scientific dental research includes all aspects of the conservative dentistry treatment which are scientifically and clinically proved with most up to date methods and tests: anthropometric, epidemiological, biochemical, immunohistochemical, electron microscopy, polarized light microscopy, light induced fluorescence, microradiography, microbiology, genetic tests, etc. Experiments in vitro, animal tests, clinical research in the last 34 years are focused in the field of prevention of dental caries, treatment of precavitated precarious lesions with nanotechnologies, preparation of hard dental tissues with most conservative techniques, adhesive restoration methods with amalgam and resins, backup in endodontics in root canals preparation methods and in pins and posts fixations. The conclusions can be focused on basic principles and refocused in the 21st century like: Dental caries is not only predictable and controlled disease but is also a polyetiological disease on a community and population levels and uni- or bi-etiological on an individual level. The minimum invasive dental concept in cariology and endodontics leads to prevention of early extractions, early prosthetic medical procedures and to lifetime dental health. This plays a key role in prevention of metabolic disorders and gastrointestinal diseases.
\end{abstract}

Key words: prevention, conservative dentistry, endodontics

Corresponding author: Assoc. Prof. Ekaterina Boteva, e-mail: e_boteva@abv.bg

$\mathrm{T}$ he active ingredients from modern foods, snacks and the mechanisms of control on frequency and numbers of their intake are mainly responsible for bacterial counts in saliva and plaque. They are also influencing the composition of the mineralized tissues in the mouth - enamel, dentin, cementum and bones $[6,13,14,34,35,40]$. The re- lations, amounts and proportions of carbohydrates, fats, proteins and minerals-macro elements, microelements - trace elements are directly leading to the phase composition and to the size of the crystallites of hydroxyapatite, fluorapatite, threecalciumphosphate, carbonate apatites, lipoproteins, fatty acids, phospholipids [1, 2, 3, 4, 42, 43, 46-49]. 

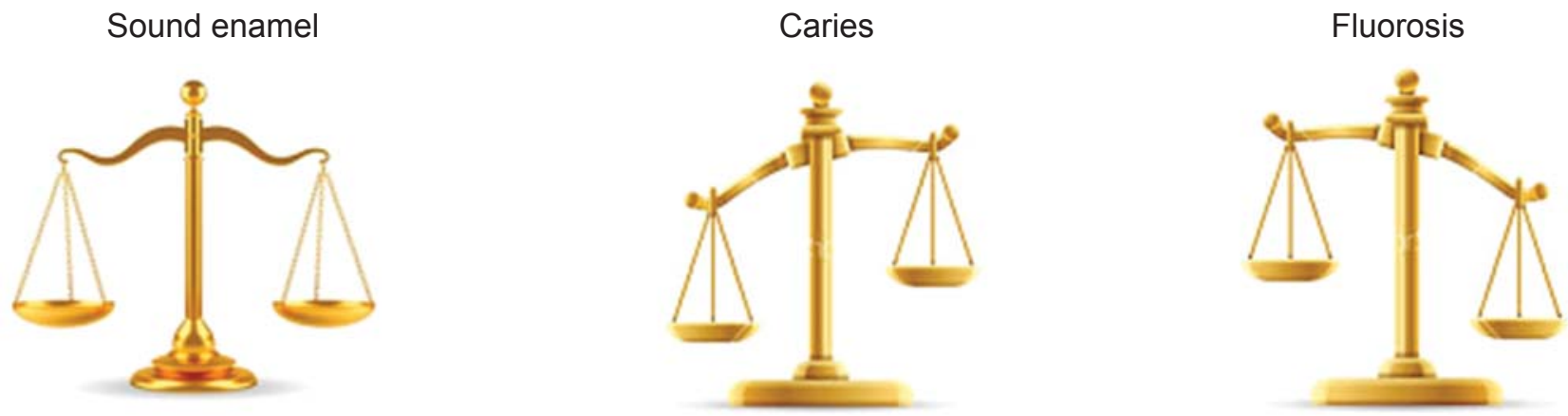

Fig. 1. Ion balance in supersaturation between demineralization and remineralization

The understanding of preresorptional (local) and postresorptional (systemic) or metabolic effects of foods, snacks and beverages in the mouth and via saliva and gingival fluids were our first basic targets since 1985. Buffer capacities of saliva are related to foodstuffs and to genetic factors such as: size and structure of the salivary glands [7, $8,9,10,28]$. Absorption of important macro elements like calcium, phosphates and fluoride are dependent on the presence or absence of systemic diseases or metabolic disorders like diabetes and obesity $[1,8,9,21]$. In the last two decades there is a significant number of patients complaining from lower salivary flow rates, burning mouth syndrome or even xerostomia. Patients with Gougerot-Sjogrens syndrome are also more than the proportions 25-30 years ago. Early metal-aesthetic crowns and bridges, polymetallic constructions, large restorations and dentures are leading to a slow but secure decrease of the salivary flow rate and changes into the composition of salivary trace and macro elements, enzymes and defense systems $[5,11,12,50]$.

Dental chair aside tests in dental patients can obtain a clear picture on dental caries activity: DMF counts, on the rates of bacteria for microbial counts of Str. mutans and Lactobacillus in saliva and salivary defense systems - with pH curves for sucrose clearance, buffer capacity tests, salivary stimulation tests $[34,35,40]$.

Early diagnosis is essential for minimum invasive treatments. In the last 25 years this was a topic with lots of speculations, marketing tricks, trade of commercial devises and "prenatal" treatment of early lesions. In a large number of dental practices and even in highly respected congresses a lot of mistakes can be observed in operative dentistry decision making of early lesions. Preventive restorative procedures are not in patients favor and if a cavitation will become a cavity with 2-3 or 4 times enlargement, this is not dental medical approach to the problem. This is a dental approach $[43,44,45,47,48]$.
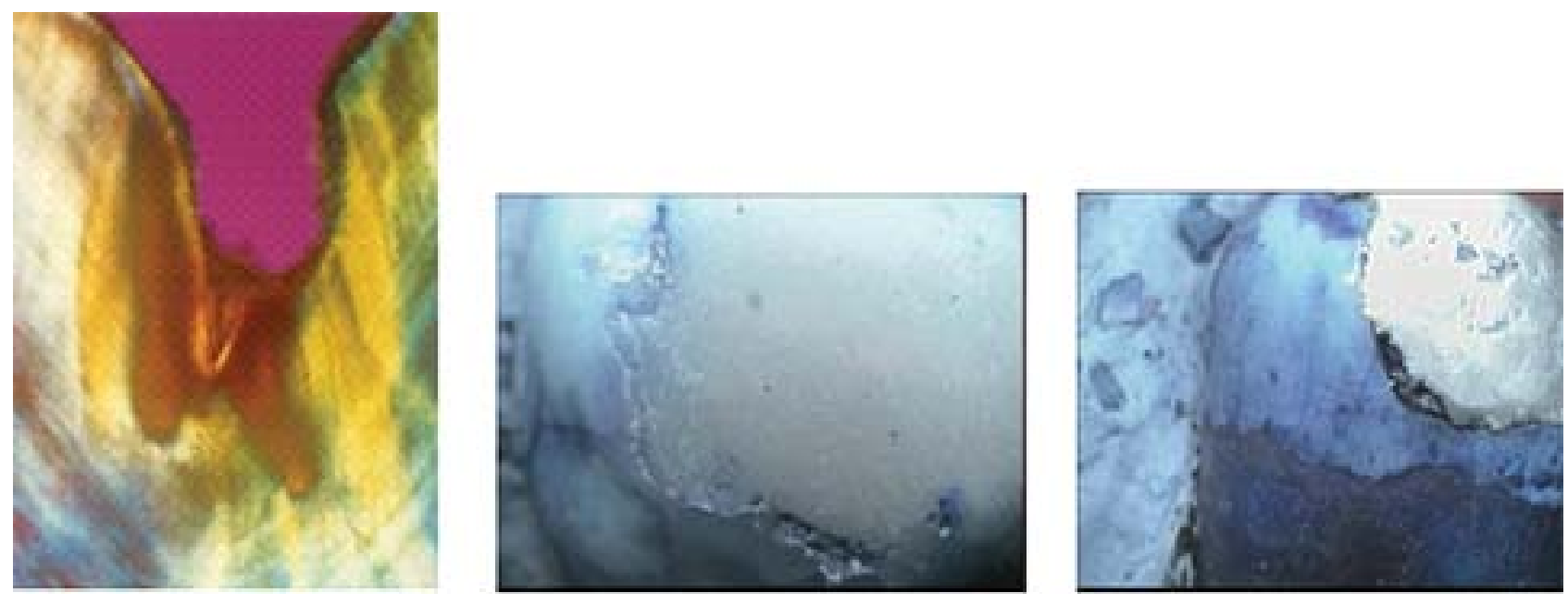

Fig. 2a Polarize light microscopy of a fissure enamel carious lesion. 2b, $\mathbf{c}$ Light induced fluorescence with Sopro-Life diagnostic devise in the diagnosis of secondary caries in resin and amalgam restorations 

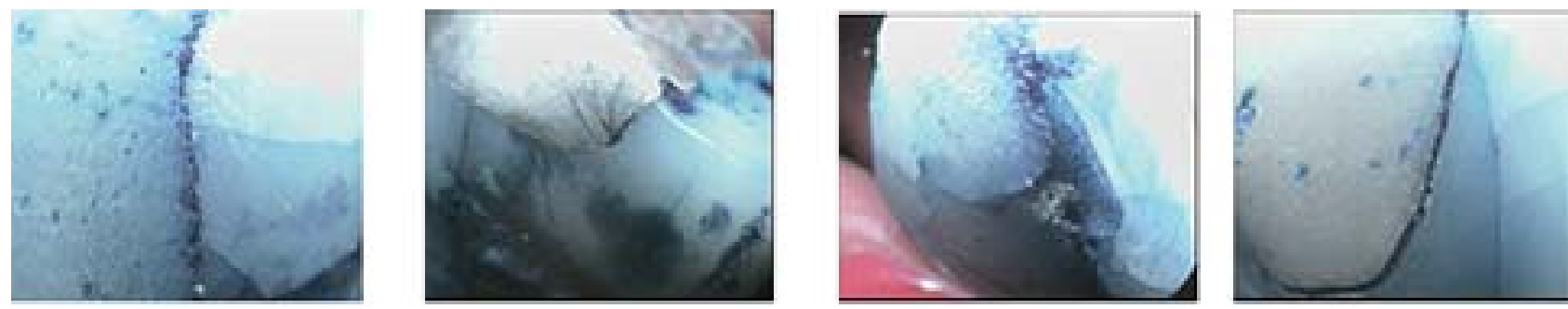

Fig. 3a, d Light induced fluorescence with Sopro-Life in the diagnosis of secondary external defects in resin materials, $\mathbf{b}$ and $\mathrm{c}$ secondary caries in resin and amalgam restorations

Best distinguished medical-dental diagnostic methods are knowledge, time, probes and dental mirrors, with respect to the individuals and family status, a biologic approach and follow up checks [36, 37, 38].

Restorations can be planned for the particular tooth, can be planned for the present status of the mouth, can be planned for both reasons, but also with a prospective for a conservative future of the patient occlusion in terms of $\mathbf{1 5 - 2 0 - 3 0}$ or even $\mathbf{4 0}$ years $[15,16,27,29,30,31,39]$. The fracture resistance depends a lot on the size of the crown, the amount of hard dental tissues, thickness of dentine, correct or incorrect presence or absence of pins and posts, conservative type of cavity preparation [26]. A very important method in the treatment of class II cavities is the saving of the marginal ridge. Another advantage of this technique is the prevention of overhangs in class II restorations [32]. Two types of class II cavities are often underestimated: tunnels and a proximal conservative adhesive type cavities, or open tunnels [15, 33].
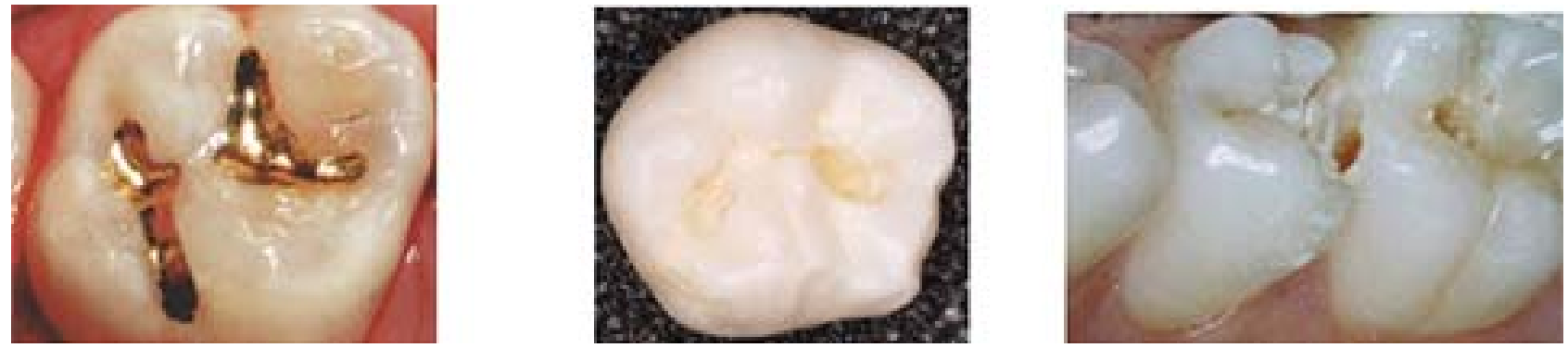

Fig. 4 a - Cohesive gold in dental caries treatment with survival rate up to 35-40 years, $\mathbf{b}$ - minimum invasive class one cavities and tunnels in the treatment of class II cavities. Special thanks to Dr Dan Henry from FL, USA for his kind permission for the use of the cohesive gold restoration photo, $4 a$

Another challenge in dental caries treatment which needs minimum invasions and treatment approaches are root caries lesions [27, 29, 40, 41]. Practically the meaning of the concept here is a correct choice of a filling material and regular use of varnishes and remineralizing solutions. Research shows that resin materials are not the best solution of this problem and glass ionomers are not a radical approach. Overcoming microleakage on the cavity walls here is problem number one [39]. Lower size of the dental crowns, which is an evolution fact, is generating a serious problem with the retention of pins [16, 30, 31].

Prevention of secondary caries and pulpitis [23] can be focused on:

1. The use of best multifunctional adhesive systems with sources of fluoride for resin materials, amalgam and even ceramics like Prime bond.
2. The correct use of dental amalgam with and without adhesives, with annual professional polishing for prevention of frequent restoration changes.

3. Best instructions for the correct use of mouthrinses.

4. A scientifically honest, clinically responsible and noncommercial approach in rejecting the electric toothbrushes.

5. Remineralization of precarious lesions, nonoperative treatments and reparations of existing large dental restorations.

6. A new revised approach to gold restorations: cast inlays, dental crowns, cohesive gold restorations.

7. Prevention of oral galvanism, polymetallic intraoral environment in contact with saliva and gingival fluid. 
8. Food induced remineralization: xylitol, sorbitol, fluoridated milk, cheese, etc.

9. Medication - therapy with calcium, collagen, and vitamins $A, E, D$ can be optimal in target groups like pregnant women, menopausal women and patients with systemic diseases.

Endodontics unfortunately still leads on the "motorway" of aggression in the last few decades. Aggressive preparations with high concentration of irrigants, with large amounts of solutions, large root canals preparations, hot and cold condenzation techniques are fact in all dental practices. Most dentists are "in love" with rotary instruments, which save time and expenses, without care about patients age, size of dentine tubules and the buffer capacity of dentine. They are often leading to practically forced endodontic treatments and to early dental losses [17, 22].
A minimum invasive sterile endo-treatments can obtain future better chances in retreatments and is essential for fixation or changes of posts. Saving larger size of active root surfaces, is much better for restorative and prosthetic purposes [18, 19]. Lower crown sizes in endodontics are even higher challenge not only for restorations after root preparation, but also for posts, for crowns and bridges on distal teeth. Saving all possible elements (longes, orifices) of pulp chambers for retentive purposes can increase the resistance to occlusal trauma [16, $20,22,24]$. Often this is in contradiction with nice $\mathrm{x}$-ray pictures, but is in patients favor. Root curvatures, resorptions, syndromes like Taurodontism, third molars can be clinical difficulties which need realistic personal knowledge on the abilities of each operator [22].
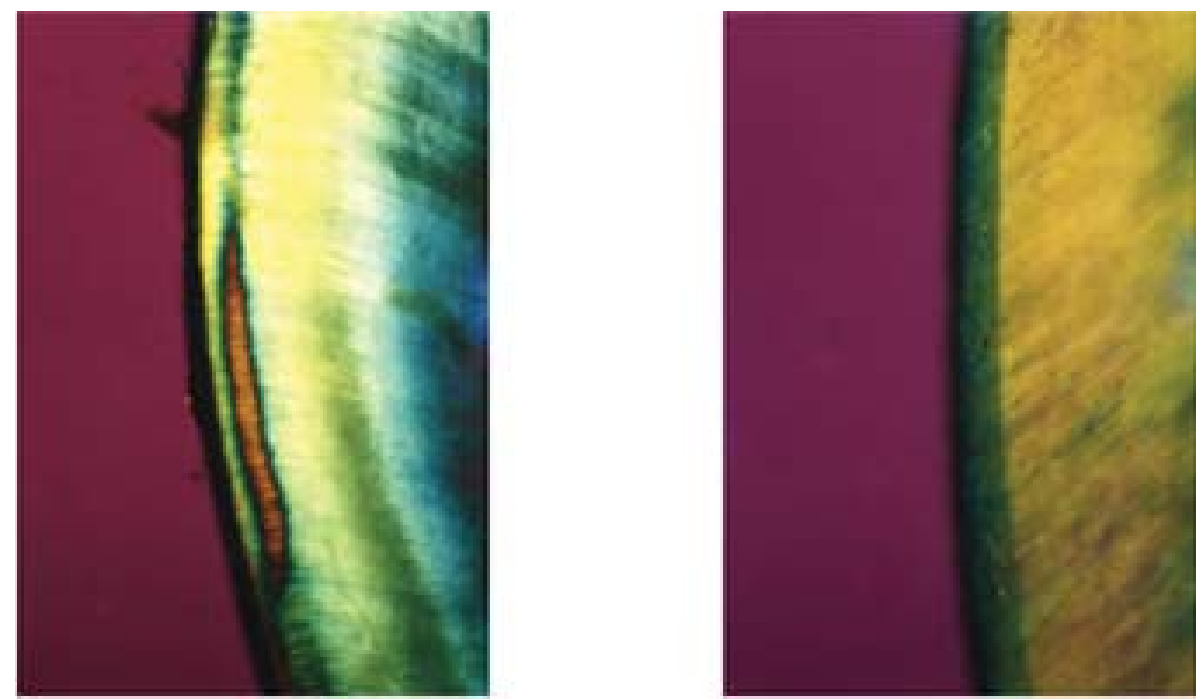

Fig. 5 (a, b). Polarized light microscopy of adhesive remineralization of teeth surfaces with 5 ppm fluoridated milk in two different magnifications. The invasion cannot be less
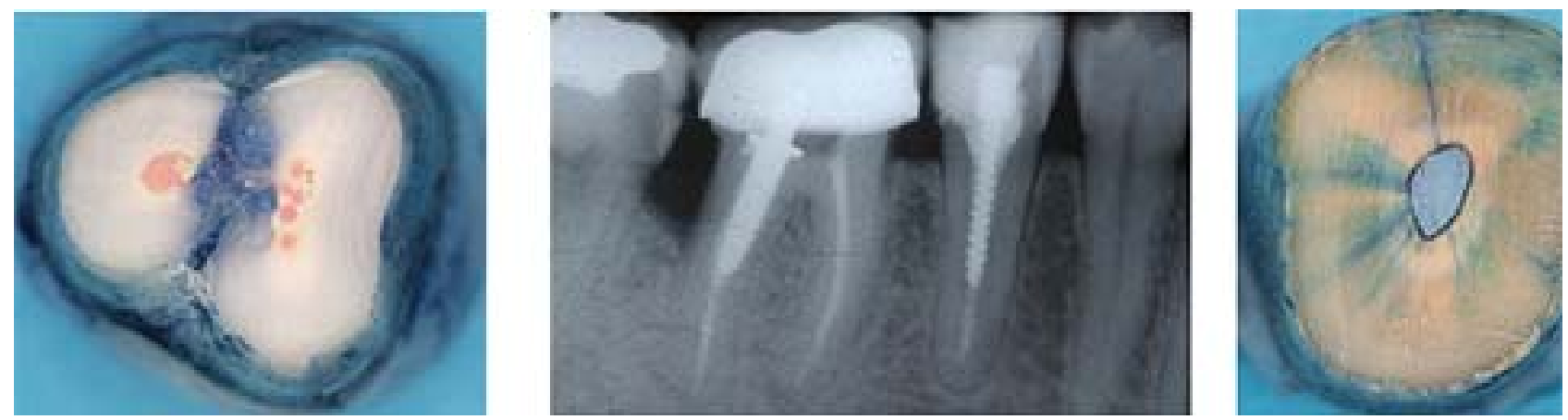

Fig. 6, a. b, c. Minimum preparation of root canals with and without metal posts cannot lead to cracks, fractures, periapical lesions and extractions 
Posts always need to be smaller for their first use, with minimum requirements in sizes and maximum respect to dentin in its thickness in the root. Always there must be a chance of fixation of a second post (enough hard dental tissues) due to periapical or intracanal pathology, or due to acute or chronic occlusal trauma reasons. In endodontics a simple rule valids $100 \%$ - beginners and megalomaniacs are always useless.

Apical enlargement and preparation higher than 40 in the treatment of pulp pathology or for prosthetic purposes can only lead to excessive amounts of pasta and gutta-percha. Any irrigations with more than $0.5 \mathrm{ml}$ per one root canal with $\mathrm{NaOCl}$ more than $0.5-1 \%$ are harmful and more damage than help $\left(25,25^{*}\right)$. They can even cause periapical lesions and osteomyelitis. Obturation of root canals is always a function from the preparation and two rules are valid:

\section{Therapia magna can damage treatment.}

2. Condensation techniques are not universal. Their indications are less than single cone ones.

Nobody wants "backup" in stone era, but lasers in diagnostic and treatments of enamel, gingiva, root canals and periapical pathology; x-rays in caries diagnosis, trauma, root fillings; $С B C T$ in use from dental caries to orthodontics treatment purposes are definitely leading to an awful amount of radiation and all its side effects, from enamel mineral loses, to papilloma's and hypoplasia, bypasses and cancer.

The conclusions in dental conservation can be focused on basic principles and refocused in the 21st century:

1. Dental caries is not only predictable and controlled disease but is also a polyetiological disease at the community and population levels and uni- or bi-etiological at an individual level.

2. The minimum invasive dental concept in cariology and endodontics leads to prevention of early extractions, early prosthetic medical procedures and to lifetime dental health. The concept is saving hard dental tissues, time of operators and patients costs and is increasing the chances for successful retreatment options. This plays a key role in prevention of metabolic disorders and gastrointestinal diseases.

\section{REFERENCES}

1. Boteva E. The impact of concentrated and refined foods in the etiopathogenesis of dental caries. Dissertation, Medical University, Sofia, 1988: in Bulgarian.
2. Boteva E, M Kostova, E Dulgerova. X-ray Diffraction Analysis of Teeth and Bones of Wistar Rats Fed on Four Diifferent Isocaloric Diets. Caries Research 25, 1991, 3, 218 Abstr. 19.

3. Boteva E. Nutritional factors in dental caries etiology. Lecture. Dental Research Seminars. University of Glasgow. Dental School. 20.03.1993.

4. Boteva E. Effects of Nutrition on Dental Caries, Salivary pH and Biochemical Patterns in Metabolic Patients. Caries Research, 27, 1993, 3, 213, Abstr .24

5. Boteva E, C Robinson, J Kirkham. Effect of Cd and Zn on the Biomineralization of Enamel, Dentine and Bone. Caries Research, 28, 1994, 3, 207, Abstr. 94.

6. Boteva E, A Rugg-Gunn, S Higham. Remineralization of White Spot Carious Lesions with Fluoridated Milk. Caries Research, 30, 1996, 4, 307, Abstr. 124.

7. Boteva E. Delivery of Fluoride to oral tissues via milk. Lecture. Dept. of Oral Biol. University of Newcastle upon Tyne. May, 1996.

8. Boteva E. Clinical studies on the effects of nutrition on the DE- and Re-mineralization of the mineralized dental tissues. Lecture. International Conference of Prophylaxis and Biomaterials. Poznan, 9-10. 06.1997.

9. Boteva E. Proteinmediated fluoridation and enamel demineralization. Lecture. International Conference on Surface and Colloid Science. 6-12.07.1997, Sofia.

10. Boteva E, AJ Rugg-Gunn. Proteinmediated Fluoridation and Enamel Remineralization: an In vitro Approach. Stoma 2000, 4, 287-291.

11. Boteva E, Dulgerova E. Study on the Influence of Hydroxyapatite Suspention on the Kinetic of Enamel Dissolution. Stoma 2001, 2, 121-124.

12. Boteva E. Sucrose clearance in patients with oral galvanism. Amb, Acta Medica Bulgarica, 30, 2003, 1, 90-94.

13. Boteva E, AJ Rugg-Gunn. Fluoride retention in enamel slabs after rinsing or drinking $\mathrm{F}$ milk or $\mathrm{F}$ water. Acta Medica Bulgarica, 31, 2004, 1, 46-52.

14. Boteva E. Adhesive remineralization in dental caries prevention. Lecture. IV International Congress of Medical SciencesICMS. Sofia, 12-15.05. 2005

15. Boteva E. Tunnel restorations of Class II Caries lesions. Caries Research, 43, 2009, 3, 231, Abstr.145.

16. Boteva E. Significance of the size of the clinical crowns of molars in cariology and endodontics. Acta Medica Bulgarica, 37, 2010, 2, 94-98.

17. Boteva E. Endodontic treatment of periapical lesions-evidence based approach. 17 Congress of ESE, Sept. 2011, Rome, Abstr. 16.

18. Boteva E. Use of posts in general dental practice. Acta Medica Bulgarica, 38, 2011, 1, 64-69.

19. Boteva $E$. Use of posts from undergraduate dental students. Acta Medica Bulgarica, 38, 2011, 1, 70-75.

20. Boteva $E$. An in vitro study on the sizes of pulp chambers and clinical crowns of molars. Acta Medica Bulgarica, 38, 2011, 2, 83-88.

21. Boteva E. Dental, oral and metabolic changes in patients with diabetes type II and hyperlipidemia. In Bulgarian language, IN: Prevention, Diagnosis and Therapy - Actual Problems. Havities, 2012, 625-628.

22. Boteva E. Endodontics: lectures, atlas and research. A monograph in Bulgarian with 21 chapters and 21 English abstracts. 2014. Sofia. Havities.

23. Boteva E. Late results of two steps application of dentin bonding agent in the biological treatment of the pulp. Abstr. In English. Problems of Dentistry, 29, 2003, 1, 3-6. 
24. Boteva E, D. lovchev. The sizes of pulp chambers of molars with severe root curvatures - in vitro comparative study. Acta Medica Bulgarica, 39, 2012, 1, 92-96.

25. Boteva E, D.I ovchev Efficiancy of working length detection and irrigation during preparation of curved root canals. Acta Medica Bulgarica, 39, 2012, 1, 97-103.

26. Boteva E, D. lovchev Efficiancy of working length detection and irrigation during preparation of curved root canals. Journal of Bass, 2012, 1, 1-4.

27. Boteva $E$. In vitro comparison of dentin bonding agent and cementum under composite material in cavities class I and II. Abstr. in English Annual Proceedings of IMAB, 8, 2002, 1, 64-67.

28. Boteva E. M. Marinova, D. Karayasheva An in vitro study of root caries in front teeth. Acta Medica Bulgarica, 39, 2012, 2. 68-71.

29. Boteva E, K. Peycheva. Detection of Dental Hypoplasia Ability of Fuorescence methods. Acta Medica Bulgarica, 40, 2013, 1, 61-64

30. Boteva E, Karayasheva, M. Marinova Frequency of root caries in teeth with sound crowns. Car. Res. 47, 2013, 5, 439, Abstr. 62.

31. Boteva E, K. Peycheva, D. Karayasheva, D. Pashkouleva. A study on fracture resistance of class IV cavities, treated with pins. Acta Medica Bulgarica, 41, 2014, 2, 43-48.

32. Boteva E., K. Peycheva, D. Karayasheva, D. Pashkouleva. A study on fracture resistance of class II cavities, treated with pins. Int J Science Res, 4, 3, 2015, 1722-1724

33. Boteva E., K. Peycheva, D. Karayasheva. Frequency of iatrogenic changes caust from overhang restorations. Acta Medica Bulgarica, 42, 2015, 2, 30-35.

34. Boteva E. Minimum invasive dental concept in prevention and conservative treatment - from research and science to practice. IJSR, 5, 2016, 11, 1325-1328.

35. Karayasheva, M. Marinova, Boteva E. Salivary flow rate, buffer capacity, microbial counts, and caries activity of young healthy subjects. Caries Research, 44, 2010, 3, 193, Abstr. 56.

36. Karayasheva D., M. Marinova-Takorova, E. Boteva. A study on salivary clearance in dental caries prediction. Arch. of the Balkan Medical Union, vol.49, 2014, 3, 319-323.

37. Karayasheva D., M. Glushkova, T. Kadiyska, E. Boteva. Association study of the role of Glut 2 receptor in dental caries susceptibility, dietary habits and body mass index-BMI. International Journal of Science and Research, 5, 2016, 3, 83-86.

38. Karayasheva D., M. Glushkova, E. Boteva, V. Mitev, T. Kadiyska Association study for the role of Matrix metalloproteinas- es 2 and 3 gene polymorphisms in dental caries susceptibility. Arch Oral Biology, 68, 2016, 9-12.

39. Karayasheva D., M. Glushkova, T. Kadiyska, E. Boteva The role of matrix metalloproteinases (MMP2 and MMP3) gene polymorphisms in dental caries susceptibility. Caries Research 50, 2016, 27, Abstr. 59.

40. Marinova-Takorova M, D. Karayasheva, E. Boteva. Evaluation of microleakage at the interface between cavity walls and giomer and silorane based resin-in vitro study. Scripta Scientifica Medicinae Dentalis, 1, 2015, 1, 38-42.

41. Marinova M., E. Boteva, K. Kalinov The role of unstimulated saliva as a risk factor for the development of root caries. Caries Research 49, 2015, p. 315, Abstr. 40.

42. Marinova M., E. Boteva, K. Kalinov A study on the connection between root caries and periodontal disease. Comptes rendus, 69, 2016, 9, 1239-1244

43. Peycheva K., E. Boteva. Methods for diagnosing dental fluorosis: Quantitative Laser fluorescence and Light-Indused fluorescence. Acta Medica Bulgarica, 40, 2013, 1, 53-60.

44. Peycheva K., E. Boteva. A Clinical study on dental fluorosis with Light Indused Fluorescence. IJSR, International Journal of Science and Research, 4, 3/2015, 1239-1241.

45. Peycheva K., E. Boteva. A comparison of different methods for fissure caries detection. Acta Medica Bulgarica, 43, 2016, 1, 30-38.

46. Peycheva K., D. Karayasheva, E. Boteva. Diagnostic abilities of light induced fluorescence - LIF with SoproLife device. Caries Research 50, 2016, 61, Abstr. 137.

47. Robinson C., R. Shore, W. Bonass et al. Identification of Human Serum Albumin in Human Caries Lesions of Enamel, Caries Research, 32, 1998, 3. 193-199.

48. Rugg-Gunn A., E. Boteva. Fluoride and Calcium Retention in the Mouth after Rinsing with F-milk or F-water. Stoma 2000, 3, .223-226.

49. Rugg-Gunn A., E. Boteva. Retention of Fluoride and Calcium in the Mouth after Rinsing with Fluoridated Milk or Fluoridated Water. Caries Research, 31, 1997, 4, 302, Abstr. 65.

50. Rugg-Gunn A., E. Boteva. Fluoride Retention in The Mouth after Rinsing with F-milk or F-water, 3 IADR/CED Sept. 1996, Berlin, Journal of Dental Research, 76, 1997, May, 5, Abstr 089, 1105, 80.

51. Rugg-Gunn A., E. Boteva. Fluoride Retention in Enamel Slabs after Rinsing or Drinking F-milk or F-water, IADR/CED Sept. 1997, Madrid, Journal of Dental Research 1998, 77 May, 5, Abstr 357, 1251, 105. 